\title{
Aproximación a la regulación constitucional de la democracia participativa en Colombia y España. Estudio comparado ${ }^{1}$
}

Approximation to the constitutional regulation of the participatory democracy in Colombia and Spain. Compared study

Recibido: 20 de mayo de 2014 - Revisado: 10 de septiembre de 2014 - Aceptado: 10 de abril de 2015

Alfredo Ramírez Nárdiz ${ }^{2}$

\section{Resumen}

Con las constituciones de 1991 y 1978 como punto de referencia, Colombia y España respectivamente han regulado diversos instrumentos propios de la democracia participativa. El presente artículo pretende responder a la pregunta de investigación de cómo se regula constitucionalmente la democracia participativa en ambos países, así como defiende la hipótesis de que aunque las dos naciones tienen regulaciones dispares, siendo la colombiana mucho más desarrollada que la española, la práctica de los dos países es bastante similar, esto es, escasa.

Palabras clave

Democracia participativa, Constitución, regulación, Colombia, España.

\begin{abstract}
With the constitutions of 1991 and 1978 as a benchmark, Colombia and Spain have respectively regulated various instruments of participatory democracy. This article aims to answer the research question of how to regulate constitutionally participatory democracy in both countries and defends the hypothesis that although the two countries have different regulations, with the Colombian much more developed than the Spanish, the practice in both countries is quite similar, is, low.
\end{abstract}

\section{Keywords}

Participatory democracy, Constitution, regulation, Colombia, Spain.

\footnotetext{
${ }^{1}$ Artículo del Grupo y Proyecto de Investigación: Poder público y ciudadanía. Transformaciones democráticas y democracia participativa.

${ }^{2}$ Doctor en Derecho Constitucional. Profesor Universidad Libre, Barranquilla, Colombia.

Correo electrónico: aramirez@unilibrebaq.edu.co

Para citar este artículo: Ramírez, A. (2015). Aproximación a la regulación constitucional de la democracia participativa en Colombia y España. Estudio comparado. Revista Civilizar Ciencias Sociales y Humanas, 15(28), 21-36.
} 


\section{Introducción}

La democracia participativa ${ }^{1}$ es una de las áreas del derecho constitucional con mayor proyección tanto teórica como práctica en el presente. Se destaca en especial el debate generado sobre ella y sobre la necesidad de ella a raíz de los distintos movimientos populares que cada vez más intensamente ya en Europa, ya en América, ya en otras partes del mundo, exigen tanto en las calles como en los Parlamentos, una mayor intervención popular en la toma de las decisiones públicas, así como un control y fiscalización más profundos de las mismas por parte de los ciudadanos: no se pretende sustituir la democracia representativa ${ }^{2}$, sino, por el contrario, lograr una mejor democracia representativa ${ }^{3}$.

La regulación de la democracia participativa, en gran parte vive esclava de cómo se concibió en los textos constitucionales de cada uno de los Estados. Textos constitucionales en ocasiones con décadas de historia y, en no poca medida, no pensados para algunas de las circunstancias que se producen en el presente, tales como la reclamación de mayor intervención directa de los ciudadanos en el gobierno de la comunidad.

La Constitución española de 1978, con apenas tres instrumentos participativos nacionales, uno regional y uno local (y muy marginal) regulados es perfecto ejemplo de lo dicho. Texto pensado sobre todo para un tiempo que ya se fue, que mantiene en su articulado normas consumidas por el uso y que muestra hoy por hoy, cómo muchas de las costuras del marco jurídico que configura coexisten cercanas a la explosión a causa de su falta de adaptación tanto a las realidades sociales, económicas y jurídicas de la actualidad, como a las demandas de la población, entre ellas: de mayor y mejor participación directa de los ciudadanos en la vida pública, esto es, exigencias de más democracia participativa ${ }^{4}$.

En este contexto, resulta en particular interesante revisar la normativa constitucional de la democracia participativa española en perspectiva con la de un país que recoja en su Constitución una regulación más extensa de la misma para, desde este estudio comparado, examinar tanto los distintos mecanismos participativos que no aparecen en el modelo español y que sí se hallan en el del otro país, así como la parca regulación de los instrumentos que sí existen en el modelo español en contraste con la más amplia de la otra nación.

Debido a su regulación y a sus circunstancias nacionales, Colombia es un modelo especialmente interesante para comparar con el español. Colombia, con su Constitución de 1991, es un buen ejemplo de país que, sometido a coyunturas críticas, decidió dotarse de un texto constitucional que, entre otros elementos, reguló una democracia participativa con un amplio número $\mathrm{y}$ variedad de herramientas participativas y que, en términos generales, pretendió aumentar la participación política de los colombianos ${ }^{5}$. Pero si cualquier reflexión sobre la democracia participativa colombiana debe partir de un acercamiento que valore su variada regulación, la situación colombiana dista mucho de ser ideal y, aunque la Constitución y las leyes que la desarrollan son en suma voluntaristas en materia de democracia participativa, la realidad del país resulta mucho más compleja ${ }^{6}$ y la correcta y perfecta aplicación de los instrumentos de la democracia participativa no es precisamente sencilla.

Antes de afrontar cualquier estudio más detallado sobre estos mecanismos, su ejecución práctica y sus resultados, es de especial interés plantear a modo de pregunta de investigación cuál es la regulación constitucional de los distintos instrumentos participativos colombianos contraponiéndola con la española, siendo la hipótesis que se defenderá y tratará de probar que si bien ambos países tienen un desarrollo constitucional diverso de la democracia participativa, los dos tienen una práctica similar por escasa. Metodológicamente, el presente artículo opta por un estudio analítico-sintético por el cual se examinan las distintas regulaciones constitucio- 
nales propias de la materia objeto de este trabajo, junto con las más relevantes características sociales e históricas de ambas naciones que en mayor modo influyeron en el proceso constituyente, para, desde dicho análisis, sintetizar los rasgos esenciales de las dos regulaciones constitucionales planteadas en la hipótesis.

\section{Panorámica de la regulación constitu- cional de la democracia participativa en España y Colombia}

A continuación, se expone y compara la reglamentación de las diferentes herramientas participativas en las constituciones de Colombia de $1991^{7}$ y de España de $1978^{8}$; también se destacan aquellos mecanismos que solo se regulan en una de las dos constituciones. Primero se expone la regulación general de la democracia participativa y después pormenorizada por instrumento.

\section{Regulación general.}

En este punto se ve la primera diferencia fundamental entre la Constitución española de 1978 y la Constitución colombiana de 1991, pues la española no contiene capítulo o sección alguna que se dedique en específico a la democracia participativa, ni artículo concreto que enumere las herramientas participativas en ella recogidas, sino que, por el contrario, distribuye los instrumentos participativos entre los distintos títulos del texto constitucional según cuál sea la función precisa de los mismos. Así, tras enunciar en el artículo 23.1 de la Constitución española el derecho fundamental a la participación política mediante representantes y directamente "los ciudadanos tienen el derecho a participar en los asuntos públicos, directamente o por medio de representantes ...", en ningún artículo se enumeran todos los mecanismos participativos, sino que estos van apareciendo según la materia en la cual deban o puedan utilizarse.

En concreto, aparecen la iniciativa legislativa popular y el referendo consultivo en el título III, capítulo II titulado "De la elaboración de las leyes"; el concejo abierto y los referendos autonómicos en el título VIII: "De la organización territorial del Estado" y en la disposición transitoria $4^{\mathrm{a}}$; y los referendos para la ratificación de la reforma constitucional en el título X: "De la reforma constitucional".

Por su parte, la Constitución colombiana de 1991, dándole una importancia preponderante a la democracia participativa ${ }^{9}$, recoge en su artículo 40 (dentro del título II: "De los derechos, las garantías y los deberes", capítulo I: "De los derechos fundamentales") siete mecanismos de participación de los ciudadanos en la conformación, ejercicio y control del poder político mezclando tanto las encuadrables en la democracia participativa, como las propias de la democracia representativa: elegir y ser elegido; participar en las elecciones, plebiscitos, referendos, consultas populares y otras formas de participación democrática; constituir partidos políticos, movimientos y agrupaciones políticas sin limitación alguna, formar parte de ellos y difundir sus ideas y programas; revocar el mandato de los elegidos en los casos y en el modo que establecen la Constitución y las leyes; tener iniciativa en las corporaciones públicas; interponer acciones públicas en defensa de la ley y la Constitución; y acceder al desempeño de funciones y cargos públicos.

Es decir, se sigue una estructura similar a la del artículo 23.1 de la Constitución española (CE) en el sentido de regular el derecho a la participación política directa y mediante representantes en un mismo artículo, si bien el artículo 40 de la Constitución colombiana no se limita a enunciar el derecho como hace el artículo 23.1 CE, sino que concreta y pormenoriza cuáles son los instrumentos específicos para ejercer tanto la participación directa como aquella mediante representantes.

Será en el artículo 103 de la carta política colombiana (título IV: "De la participación democrática y de los partidos políticos", capítulo I: 
"De las formas de participación política") donde se listen los instrumentos de la democracia participativa y se indique que son mecanismos de participación de la ciudadanía en el ejercicio de la soberanía: el voto ${ }^{10}$, el plebiscito, el referendo, la consulta popular, el cabildo abierto, la iniciativa y la revocación de mandato. Se puede observar, en definitiva, cómo, antes de regular ningún instrumento participativo concreto, la Constitución de Colombia cita y enumera en conjunto todas estas herramientas, cosa que no hace la Carta Magna española.

\section{La consulta popular.}

Entendiendo el término consulta popular como expresión amplia que incorpora en su seno toda pregunta hecha a la ciudadanía ya sea referendo, plebiscito o cualquier otra forma que adopte, dentro de la práctica de la democracia participativa, dirigirse a los ciudadanos planteándoles una cuestión a decidir $^{11}$, la regulación constitucional de la misma en España se circunscribe a tres tipos de referendos: el consultivo del artículo 92; los autonómicos del título VIII y la disposición transitoria $4^{\text {a }}$; y el de ratificación de la reforma constitucional del título $\mathrm{X}$.

El referendo consultivo se prevé para aquellas decisiones políticas de especial trascendencia y será convocado por el rey a propuesta del presidente del gobierno, previa autorización del Congreso de los Diputados. $\mathrm{Su}$ ámbito territorial ha de entenderse que es el nacional, es decir, el conjunto de toda España, pues la Constitución indica que dichas decisiones políticas de especial importancia se someterán a referéndum consultivo de "todos los ciudadanos", debiendo tener por tales a todos los españoles.

Esto es especialmente relevante de cara a examinar la posibilidad de realizar referendos consultivos de ámbito regional/autonómico en España, como se propone desde determinados escenarios, en los que solo votarían los habitantes de dicha región. En función de lo dicho, no sería posible, al tener que llamar a votar a toda la ciudadanía española en cualquier referendo consultivo. Para realizar referendos consultivos de ámbito territorial menor al nacional sin evadir la legalidad constitucional sería más que recomendable que se reformara la Constitución o, como mínimo, que se reformara en un sentido favorable la ley orgánica 2 de 1980, del 18 de enero, sobre la regulación de las distintas modalidades de referendo, la cual desarrolla la Constitución.

El referendo para la ratificación de la reforma constitucional se regula como dos diferentes referendos según la materia sometida a ellos: el $167 \mathrm{CE}$ prevé, para aquellas reformas de la CE que no afecten al título preliminar, a los derechos fundamentales y al título II, un referendo de realización no obligatoria, que se convocará cuando en un plazo no mayor de quince días desde la aprobación de la reforma constitucional un $10 \%$ de cualquiera de las cámaras lo solicite; el 168 prevé, para las reformas totales de la $\mathrm{CE}$ o para aquellas que sí afecten al título preliminar, a los derechos fundamentales y al título II, un referendo de realización obligatoria que culminará el proceso de reforma constitucional; el resultado de ambos referendos será vinculante.

Los referendos autonómicos se recogen en los artículos 151 y $152 \mathrm{CE}$ y se disponen para revalidar los distintos pasos de creación de las comunidades autónomas (esto es, iniciativa autonómica y aprobación del Estatuto de Autonomía. Estos procesos de creación de las Comunidades Autónomas (CCAA) se realizaron entre 1979 y 1983), así como para la confirmación de la reforma del Estatuto de Autonomía en aquellas CCAA que previamente hubieran ratificado la aprobación del mismo mediante referendo o que establezcan que para futuros estatutos así será necesario; estos referendos tendrán por ámbito territorial las CCAA cuya iniciativa autonómica, estatuto, o reforma de estatuto se corrobore; la disposición transitoria 
$4^{\mathrm{a}}$ prevé el caso específico de una hipotética unión de la CCAA de Navarra a la CCAA del País Vasco y la necesidad de un referendo que la convalide (referendo cuyo ámbito territorial no queda determinado en la $\mathrm{CE}$ ).

La práctica de los distintos referendos recogidos por la Constitución española ha sido, en sus más de treinta y cinco años, apenas testimonial: dos referendos consultivos -Organización del Tratado del Atlántico Norte (Otan), 1986 y Constitución Europea, 2005-, ninguno de ratificación de la reforma constitucional, aun y las dos reformas realizadas (1992 y 2011), y los referendos autonómicos se han ejecutado en solo cuatro de las diecisiete CCAA potencialmente posibles: Cataluña, País Vasco, Galicia y Andalucía (RamírezNárdiz, 2012).

En el contexto regional y local, tal como confirma el Tribunal Constitucional en sentencias como la citada STC 103 de 2008, de 11 de septiembre (y a salvo de la legislación autonómica sobre consultas populares por vía de referendo como, por ejemplo, la catalana), la pregunta a los ciudadanos ya no se denomina referendo, sino que pasa a llamarse consulta popular, ya no se regula en la Constitución, sino en legislación nacional derivada y, sobre todo, en legislación de carácter autonómico. Por ello no compete a este punto del texto.

Por su parte, en Colombia las preguntas a la ciudadanía son de tres clases según se consulte sobre una norma jurídica (referendo), una decisión política previamente tomada por el ejecutivo correspondiente (plebiscito) o una decisión política aún no tomada por el ejecutivo (consulta popular). Se concentran en los artículos 40,103, 104, 105, 106, 170, 241, 297, 307, 319, 321, 374, 377, 378 у 379 de la Constitución colombiana de 1991. Así, se recogen las preguntas nacionales, regionales, locales y una modalidad territorial para el ingreso a una provincia de municipios que estén interesados en ello.
El artículo 104 indica que el presidente de la República, con el apoyo de los ministros y el Senado, puede convocar consultas populares que serán vinculantes y que no deberán ser citadas en concurrencia con otra elección. El 105 plantea la misma posibilidad en manos de los gobernadores y alcaldes en los ámbitos de su competencia territorial. El 319 contempla la posibilidad de dos o más municipios que tengan características de área metropolitana de vincularse como entidad administrativa y de someter dicha vinculación a consulta popular de sus vecinos.

El artículo 321.4 regula la consulta popular para el ingreso a una provincia de aquellos municipios que así lo deseen y lo voten. Más allá de estas dos últimas modalidades (de la segunda se podría buscar una lejana similitud con la disposición transitoria $4^{\mathrm{a}}$ de la Constitución española, por la incorporación de un territorio a otro), los dos elementos más llamativos de la regulación constitucional colombiana en relación con la regulación constitucional española posiblemente sean el carácter vinculante de la consulta popular en Colombia, frente al carácter consultivo de la española, así como la sencillez y naturalidad (propia de un texto trece años posterior con un diferente contexto constituyente) con la que se regulan las preguntas regionales y locales, cosa que en España, no solo no sucede así, sino que la reglamentación de estas consultas populares de ámbito territorial menor (en especial las regionales o autonómicas) es polémica y genera sentencias del Tribunal Constitucional a raíz de los conflictos entre el Estado y algunas regiones con aspiraciones nacionalistas.

En cualquier caso, en Colombia y desde 1991, solo ha habido una pregunta de ámbito nacional a la ciudadanía (el referendo contra la corrupción, el desparrame de las finanzas públicas y para fortalecer la democracia de 25 de octubre de 2003, del cual solo una de sus quince preguntas se aprobó ${ }^{12}$ ). Esto permite visualizar que, independientemente del mayor 
y más variado desarrollo constitucional de las preguntas a la ciudadanía en Colombia, la práctica tanto de Colombia como de España es muy reducida.

\section{La iniciativa popular.}

En la Constitución española se recoge únicamente la iniciativa legislativa popular en el artículo 87.3. Es una iniciativa para la presentación, previa recolección de 500.000 firmas, de proposiciones de ley que el Congreso podrá o no aceptar y que, si acepta, podrá modificar en todo aquello que considere oportuno a lo largo de la tramitación parlamentaria. Se descartan de esta iniciativa todas aquellas materias relativas a la ley orgánica (derechos fundamentales, libertades públicas, régimen electoral general, estatutos de autonomía de las regiones e instituciones del Estado), tributarias, de carácter internacional o en la prerrogativa de gracia. Es decir, en gran medida se excluyen las cuestiones más importantes de la vida pública del país. Ninguna iniciativa ha acabado convertida en ley.

La iniciativa popular aparece en los artículos 40,103, 106, 154, 155 y 375 de la Carta Magna colombiana. Así el artículo 154 indica que las leyes colombianas pueden tener su origen en las cámaras, el gobierno nacional, la Corte Constitucional, el Consejo Superior de la Judicatura, la Corte Suprema de Justicia, el Consejo de Estado, el Consejo Nacional Electoral, en el procurador general de la nación, en el contralor general de la República, pero también en la iniciativa popular en los casos previstos en la Constitución.

En este sentido, el artículo 155 apunta que los ciudadanos podrán entregar proyectos de ley siempre que estos sean presentados por un mínimo del $5 \%$ (art. 375) de los ciudadanos inscritos en el censo electoral. $\mathrm{Su}$ iniciativa será tramitada por el Congreso mediante trámite de urgencia y tendrán derecho a nombrar un representante que será oído por las cámaras durante todo el proceso legislativo. Por su parte, el artículo 106 señala que los habitantes de las entidades territoriales podrán presentar proyectos sobre asuntos que sean de competencia de la respectiva corporación pública, la cual estará obligada a tramitarlos, así como podrán decidir sobre las disposiciones de interés de la comunidad a iniciativa de la autoridad o corporación correspondiente, pero también a iniciativa de no menos del $10 \%$ de los ciudadanos inscritos en el respectivo censo electoral. Al igual que en el caso español, tampoco hay iniciativas que hayan dado lugar a leyes nacionales.

\section{La revocatoria de mandato.}

La Constitución española no la regula. La Constitución colombiana la recoge en el artículo 40 indicando que, para hacer efectivo el derecho de los ciudadanos a participar en la conformación, ejercicio y control del poder político, una de las facultades que dichos ciudadanos tienen es revocar el mandato de los elegidos en los casos y en la forma que establecen la Constitución y la ley. El artículo 103 reincide en la cuestión al estipular que la revocatoria de mandato es uno de los mecanismos de participación del pueblo en el ejercicio de su soberanía.

Como expresa este mismo artículo, la revocatoria ha de ser regulada por ley (que, junto para con el resto de instrumentos participativos, es la ley 134 de 1994 -reformada por la ley 741 de 2002-, así como la ley 131 de 1994 en lo relativo al voto programático). Directamente relacionada con la revocatoria de mandato hay que entender la institución del voto programático regulado en el artículo 259, que advierte que aquellos que elijan gobernadores y alcaldes, imponen por mandato a aquel que eligen el programa que presentó al inscribirse como candidato, remitiendo a la ley la reglamentación de esta institución. Del incumplimiento de este programa procederá la justificación para solicitar la revocatoria. La 
práctica de la revocatoria es igualmente escasa, pero sí que se han dado casos de revocatorias exitosas (en 2013 hubo 35 revocatorias de las que solo dos prosperaron $)^{13}$.

\section{El cabildo abierto.}

Se muestra en el artículo 140 de la Constitución española, el cual se limita a citarlo indicando que una ley regulará las condiciones en que proceda el régimen de concejo abierto. En la Constitución colombiana aparece en el artículo 103, que lo concibe como uno de los mecanismos de participación del pueblo en el ejercicio de su soberanía. La práctica del concejo abierto en España es casi testimonial al limitarse a municipios muy poco poblados y/o aislados, de montaña, etc. En Colombia existe un desarrollo mayor, pero no sobresaliente si se tiene en cuenta el número total de municipios del país: en 2013 se hicieron 89 y se aprobaron $48^{14}$.

Basta, con una breve revisión de la regulación constitucional de los instrumentos participativos tanto en España como en Colombia, así como una sucinta recapitulación de su práctica para comprobar que si bien el modelo colombiano regula más instrumentos que el español, en la praxis, el uno y el otro los ejecutan de un modo similar, esto es, escaso, siendo apenas el ámbito local colombiano (cabildos y revocatorias) el único que destaca y solo por comparación con los restantes tanto dentro de sus fronteras como respecto de España.

\section{Marco sociohistórico de redacción de la regulación de la democracia participativa en España y Colombia}

Vista la regulación constitucional de la democracia participativa en España y Colombia, y ante el hecho de que la segunda es más amplia que la primera, la inmediata pregunta que surge es porqué es así, porqué dicha regulación es esta y no otra. Para entender las razones latentes detrás de la más desarrollada regulación de la democracia participativa en Colombia que en España, más allá del hecho evidente de que al ser más reciente es lógico que la Constitución de 1991 recogiera una regulación más desarrollada de la democracia participativa al ser la misma igualmente reciente, es posible hacer una propuesta de algunos de los motivos históricos y sociales que pudieron latir en el constituyente de ambas naciones cuando decidió normar de un modo determinado y no de otro la democracia participativa en los respectivos textos constitucionales.

\section{España.}

Con la muerte del dictador Francisco Franco el 20 de noviembre de 1975 comienza en España el periodo popularmente conocido como "La Transición". Ya se fije el final de este momento histórico el 6 de diciembre de 1978, al ratificarse en referéndum la Constitución, ya el 28 de octubre de 1982 con la victoria del Partido Socialista Obrero Español (PSOE) como primer partido de izquierda en ganar unas elecciones generales tras el término de la dictadura, el logro más importante de este tiempo fue pasar de una dictadura militar a un gobierno democrático equiparable a cualquier otro de Europa en no más de una década. Momento culminante fue la elaboración, aprobación y ratificación popular de la Constitución de 1978. Hija de este texto, la democracia participativa española viene, en gran medida, determinada por cómo se reguló en él y cuáles fueron los motivos que llevaron a tal regulación.

A la vista de la Constitución, es viable comprobar cómo el constituyente de 1978 y el legislador que lo desarrolló, regularon de un modo restrictivo la democracia participativa. Apenas se incorporaron a la Constitución unos pocos instrumentos participativos, se limitó su ejercicio efectivo tanto como se pudo (basta con ver la lista de materias excluidas de la iniciativa legislativa popular por el art. 87.3 $\mathrm{CE}$ ), se redujo al mínimo la intervención de los ciudadanos en las herramientas participativas 
(no pueden proponer ningún tipo de referendo, por ejemplo), cuando se supone que dichos mecanismos buscan fomentarla, $y$, en términos generales, se construyó un modelo basado casi en exclusiva en la democracia representativa $\mathrm{y}$, en particular, en el rol de los partidos políticos, a los que se elevó a la categoría de seudoinstituciones del Estado, intermediarios necesarios entre los ciudadanos y la toma de decisiones políticas ${ }^{15}$.

Las razones de esta restrictiva regulación habría que ir a buscarlas a la voluntad del constituyente, recién terminada la dictadura, crear una democracia parlamentaria estable y edificada alrededor de unos partidos políticos fuertes y sólidos. Se tenía no poco temor a que unos demasiado desarrollados instrumentos de la democracia participativa abrieran la puerta de la política a fuerzas extraparlamentarias, extremistas, o que quisieran frenar o incluso invertir el proceso de apertura democrática. Se desconfiaba de la democracia participativa como modelo, especialmente al conocer la experiencia italiana con la misma, experiencia que se consideraba como negativa y que no se deseaba emular. En palabras de Alzaga (1996):

Nuestros constituyentes, que, de un lado, no habían olvidado los referendos franquistas, sistemáticamente enmarcados en la propaganda oficial y unidireccional en favor del sí de turno y que, de otro, deseaban consolidar el sistema de partidos políticos como principales herramientas de la democracia representativa y que, además, albergaban algún temor a las posibilidades que podían tener los grupos extremistas de derecha e izquierda a la hora de manejar mecanismos extraparlamentarios, fueron muy cautos en la instauración de dispositivos de participación popular directa (p. 295).

Igualmente, en lo relativo a la experiencia italiana apunta Alzaga (1978):

El hecho de que la inmensa mayoría de las fuerzas políticas concurrentes en nuestro proceso constituyente estimase como negativa la experiencia italiana, donde el referendo abrogativo ha generado no pocos problemas y enturbiado un tanto el ambiente político, lo que ha facilitado un campo de juego idóneo a los partidos políticos marginales y extraparlamentarios $\mathrm{y}$, a la par, ha permitido sacar de los muros de los edificios que albergan las Cámaras las contiendas políticas para llevarlas a la calle, pesó en forma determinante [...] (p. 581).

Es decir, la regulación constitucional (y, derivada de ella, la regulación legal de los años posteriores) de la democracia participativa española parte de una serie de precauciones y presunciones negativas por parte del constituyente, convirtiéndola en un breve conjunto de instrumentos que más pretendían satisfacer un mínimo de participación directa de los ciudadanos en la vida pública que, realmente, fomentar dicha participación o, siquiera, hacerla lo más sencilla y accesible posible.

\section{Colombia.}

En Colombia las circunstancias y los resultados de las mismas fueron muy diferentes. El proceso constituyente colombiano vino precedido de una situación nacional crítica, una de las conclusiones que se extrajeron fue la necesidad de hacer una Constitución que intentara dar más participación a los ciudadanos. Este ánimo quedó de manifiesto incluso en el hecho de que uno de los grandes promotores de elaborar una nueva Constitución, fuera un movimiento participativo ciudadano encabezado por estudiantes universitarios, los cuales llamaron a la ciudadanía a votar por una Asamblea Constituyente.

En los años previos a la elaboración de la Constitución de 1991 la situación del país resultaba de una complejidad y dificultad extraordinaria, donde el narcotráfico, el paramilitarismo y la guerrilla creaban un terrible clima de violencia y donde el modelo político fomentaba un bipartidismo generador de corrupción que hacía muy difícil la participación de otras fuerzas 
políticas y que deslegitimaba enormemente la política ante los ciudadanos.

En este marco, y tras el asesinato del candidato presidencial Luis Carlos Galán, unos veinte mil estudiantes universitarios de Bogotá participaron en 1989 en la "Marcha del Silencio" (Gaitán ya había hecho otra marcha con este mismo nombre en el pasado), con la cual manifestaron su rechazo a cualquier acto de violencia, más allá de ideologías, exigieron el respeto de los derechos humanos y expresaron su apoyo a las instituciones democráticas, pidiendo simultáneamente la depuración de estas, así como de la policía, el ejército y los partidos políticos.

Desde ese momento, se propuso que junto con otras seis propuestas oficiales sometidas a votación ciudadana el 11 de marzo de 1990, se sometiera también al voto popular la convocatoria de una Asamblea Constituyente para hacer una nueva Constitución, lo que se conoció popularmente como la "Séptima Papeleta". El registrador nacional indicó que esta propuesta estaba fuera de la legalidad de la convocatoria, pero que tampoco era causa de anulación de la misma, así que los ciudadanos la votaron junto con las otras seis.

Una vez votada, y al obtener un elevado apoyo ciudadano cercano a los dos millones de papeletas (García-Jaramillo, 2013, p. 140), la propuesta se institucionalizó a través del decreto legislativo 927 de 3 de mayo de 1990, el cual autorizaba a que en las elecciones presidenciales del 27 de mayo se contabilizaran los votos a efectos de organizar una Asamblea Constitucional. La Corte Suprema, al pronunciarse sobre la constitucionalidad de este decreto, abrió la puerta a la elaboración de una nueva Constitución (y no solo a reformas sobre la Constitución de 1886 , como pretendía el decreto) y permitió que, tras el decreto 1926 y otro pronunciamiento favorable de la Corte Suprema, se convocara la Asamblea Constituyente y de ella surgiera la actual Constitución de 1991. En palabras de Leiva-Ramírez y Muñoz-Gonzáles (2011):
El proceso que condujo a la promulgación de la Constitución Política de 1991 fue producto de un anhelo nacional que deseaba una mayor participación política en las decisiones que los afectaban, especialmente en la búsqueda de un escenario que permitiera la estabilización hacia la paz nacional que aparentemente se estaba alcanzando con la desmovilización de grupos guerrilleros como el M-19, pero que se estaba viendo afectada con la entrada de la violencia que producían los grupos de narcotraficantes [...], lo que conllevó que la sociedad reaccionara, siendo el movimiento estudiantil su mayor exponente a través del movimiento conocido como la "Séptima Papeleta", el cual motivó a los gobiernos de Virgilio Barco y César Gaviria a diseñar los instrumentos jurídicos que permitieran una modificación a la Constitución Nacional de 1886 (pp. 124-125, 131).

No son pocos, sin embargo, los autores que consideran que la Constitución de 1991 defraudó estos anhelos, tanto la búsqueda de paz, como una mayor democracia participativa ${ }^{16}$. En gran medida, en este contraste entre la realidad constitucional y la realidad material es donde se puede rastrear el origen de que si bien la regulación constitucional colombiana de la democracia participativa es mayor que la española, su práctica es igualmente exigua en casi todos los ámbitos.

Resulta por ende crucial, tanto en el caso español como en el colombiano, conocer mínimamente estos trasfondos sociales e históricos de ambas naciones para comprender algunos de los motivos del menor, en el caso español, y mayor, en el caso colombiano, desarrollo constitucional de la regulación de la democracia participativa. Regular del modo en que se hizo la democracia participativa, más allá de que las razones para hacerlo fueran acertadas o equivocadas, no fue una decisión ligera o al azar del legislador, sino que detrás de ella hubo una serie de motivaciones enraizadas en el pasado nacional inmediato, en las valoraciones de oportunidad que en ambos casos hicieron los diferentes constituyentes y en las expectativas 
y esperanzas que se depositaron en el texto constitucional.

\section{Conclusiones}

La visión conjunta de la regulación constitucional de Colombia y España en materia de democracia participativa, en perspectiva con el conocimiento de sus realidades sociales e históricas en el momento de redactar dicha normativa constitucional, facilita proponer una serie de conclusiones:

El diferente momento histórico y social que vivían los dos países, así como las distintas necesidades nacionales que los dos constituyentes priorizaron al redactar las constituciones, se manifiesta en las regulaciones constitucionales resultantes de la democracia participativa. Así, el constituyente español deseaba, tras cuarenta años de dictadura, consolidar la democracia representativa alrededor de los partidos políticos ideológicos de masas. Por ello incluyó una mención específica a los partidos en el título preliminar de la Constitución ${ }^{17}$ y por ello trató de regular la democracia participativa del modo más restrictivo posible, por miedo a que la misma fuera usada por fuerzas extraparlamentarias y extremistas, así como por cierta precaución derivada de la opinión negativa que se tenía sobre la experiencia italiana con la democracia participativa $^{18}$.

En el caso colombiano se produce un fenómeno en gran medida inverso, pues uno de los problemas que se diagnosticó fue precisamente la falta de participación y uno de los remedios que se ideó fue la introducción en la Constitución de 1991, de un número considerablemente elevado de instrumentos participativos cuyo objetivo era permitir a la ciudadanía desarrollar una mayor participación y control de sus gobernantes. El propio proceso constituyente tuvo como uno de sus precedentes inmediatos un movimiento participativo estudiantil que promovió la organización de una Asamblea Constituyente y que lo logró a través de la, inicialmente no oficial pero después reconocida por la Corte Suprema, votación de la llamada "Séptima Papeleta".

Derivado de lo anterior, es posible comprobar cómo la regulación de la democracia participativa en España es parca ${ }^{19}$ en comparación con la colombiana, la cual reglamenta de una manera más amplia las herramientas participativas y recoge mecanismos de participación que ni siquiera se regulan en España.

No obstante, si bien la regulación sobre democracia participativa recogida en la Constitución de 1991 y en las leyes que la desarrollan configura un modelo de democracia participativa completo, las circunstancias colombianas -políticas, económicas, relativas a la seguridad ciudadana y a la compleja garantía de los derechos humanos en diversas zonas del país- hacen caer a este modelo en una situación similar a la que padecen otros países de Iberoamérica que también poseen elaborados sistemas de democracia participativa. Esto es, una situación de alto desenvolvimiento teórico, pero modesto desarrollo práctico.

También se podría considerar que la democracia participativa colombiana ha tenido hasta el momento una utilización limitada debido a otros motivos, tales como los requisitos que impone la ley 134 de 1994, el presidencialismo que caracteriza la vida política nacional, la situación de violencia que aún vive el país y que restringe o desvirtúa en no poco modo la participación política de los ciudadanos, el clientelismo y la corrupción que afectan a una parte no desdeñable de la democracia colombiana, etc. (Thomas-Acuña, 2008, p. 16).

Empero, lo dicho no significa que la democracia participativa no tenga futuro en Colombia o que su práctica sea marginal en España. Al contrario, precisamente el futuro y la profundidad de la democracia colombiana pasa en gran medida por potenciar la práctica de sus instrumentos participativos y, en España, aun y 
la parálisis de la democracia participativa en el escenario nacional y sus barrocos desarrollos regionales, en el ámbito local sí que se práctica. Pero esto significa que este futuro requerirá de reformas.

En Colombia cambios que posiblemente no afecten tanto a la regulación de la democracia participativa, como al conjunto de las costumbres y tradiciones democráticas de la sociedad colombiana, asentando las dinámicas y prácticas democráticas más allá de lo que en estricto imponga la norma y dotando al país de una mayor estabilidad institucional y de un sólido respeto por el modelo democrático en todos los escenarios institucionales y sociales. Evidentemente, esto necesita de un elemento previo, cual es la imprescindible pacificación definitiva de la nación.

Por su parte, en España se hace necesario un replanteamiento general de la regulación de la democracia participativa, que asuma que la realidad jurídica, económica y social del siglo XXI nada tiene que ver con la del periodo constituyente 1977-1978, y que amplíe fuerte y decididamente la regulación de los instrumentos participativos como medio para encauzar gran parte del descontento ciudadano que en el presente se vive en el país.

Se podría en definitiva concluir que, ciertamente el desarrollo constitucional de la democracia participativa en ambos países es dispar, siendo el colombiano mayor que el español. Sin embargo, y por los distintos motivos citados, diferentes en una nación respecto de la otra, la práctica y el ejercicio de la democracia participativa es semejante en las dos naciones, siendo que las dos la practican escasamente.

\section{Notas}

1 Para una conceptualización en profundidad de la democracia participativa se proponen las obras de Ramírez-Nárdiz (2010;
2012). Quepa señalar en este sentido, que la definición mayoritariamente aceptada por la doctrina, indica que la democracia participativa es aquel conjunto de instrumentos participativos cuya introducción se pretende en la democracia representativa, al objeto de complementarla mediante una más alta participación de los ciudadanos en la toma de decisiones públicas, así como en el control de sus gobernantes y todo ello con el propósito final de ahondar en la democracia.

La democracia participativa, tal como se la concibe en el presente, no pretende sustituir a la representativa (eso sería democracia directa), ni se circunscribe a ser un medio para el fortalecimiento del parlamentarismo (Kelsen, 1977), sino que busca su complemento y mejora dando lugar a una sociedad que recupere el espacio público (Habermas, 1998) y que así supere versiones elitistas de la democracia (Sartori, 2003) como la defendida entre otros por Schumpeter (1971).

2 "En rigor, cuando se trata de verdaderos procesos democráticos, la democracia participativa no solo no desplaza a la representativa, sino que la complementa, situándose en un plano diferente que permite minimizar los riesgos de alejamiento entre representantes y representados, a la búsqueda de una mejor calidad de la representación $[\ldots]$ no existe alternativa a la democracia representativa, que es la única democracia posible, que podrá ser susceptible de mejora, de incremento de la participación, de mayor aproximación a los individuos cuya voluntad es necesariamente el punto de partida democrático de toda fabricación de la voluntad política" (FernándezMiranda, C.C \& Fernández-Miranda, C.A. 2003, pp. 28-30).

${ }^{3}$ Entendiendo por democracia representativa lo que expresa Manin (2006): "Desde que se inventó esta forma de gobierno, se han observado invariablemente cuatro principios en los regímenes representativos: 1) quienes gobiernan son nombrados por elección con intervalos 
regulares. 2) La toma de decisiones por los que gobiernan conserva un grado de independencia respecto de los deseos del electorado. 3) Los que son gobernados pueden expresar sus opiniones y deseos políticos sin estar sujetos al control de los que gobiernan. 4) Las decisiones públicas se someten a un proceso de debate (p. 7)".

${ }^{4}$ De esta situación surge en España en 2011 el movimiento popular $15 \mathrm{M}$, amalgama del desencanto popular, que se caracterizaba por: disgusto con el modelo político actual y, en particular, con los partidos políticos y los políticos profesionales; rechazo del sistema económico capitalista, especialmente del capitalismo financiero; solicitud de mayor participación ciudadana y de mayor control de los ciudadanos sobre sus representantes; solicitud de profundización y mejora de la democracia; etc. En palabras de Presno-Linera (2012): "este entramado ha venido compartiendo el rechazo de una serie de disposiciones normativas y/o de aplicación práctica de las mismas que, en el ámbito político y constitucional, cuestiona que tengamos una democracia real en el sentido reclamado por Habermas (1998): 'una democracia en la que los procesos de formación de la voluntad política institucionalizada jurídicamente estén conectados con, y permanezcan porosos a, la formación de una opinión pública no formalmente articulada, lo más argumentativa posible [...] (p. 38)"'.

5 "Estableció instituciones y mecanismos para ampliar la representación política de las minorías y de las fuerzas distintas del bipartidismo tradicional, para tratar de reducir el clientelismo y la corrupción y para aumentar el control ciudadano sobre la actividad del Estado. La participación política fue ampliada en el ámbito municipal con la creación de las juntas administradoras locales y en el departamental, con la elección popular de gobernadores" (Alemán-Peñaranda \& AmorochoMartínez, 2001, p. 73).

${ }^{6}$ Ejemplo especialmente llamativo y descriptivo de la complejidad política colombiana es el fenómeno de los desplazados forzados, entendidos estos como "toda persona que se ha visto forzada a migrar dentro del territorio nacional abandonando su localidad de residencia o actividades económicas habituales, porque su vida, su integridad física, su seguridad o libertad personales han sido vulneradas o se encuentran directamente amenazadas con ocasión de cualquiera de las siguientes situaciones: conflicto armado interno; disturbios y tensiones interiores, violencia generalizada, violaciones masivas de los derechos humanos, infracciones al Derecho Internacional Humanitario u otras circunstancias emanadas de las situaciones anteriores que puedan alterar drásticamente el orden público" (art. 1 de la ley 387 de 1997).

Tal vez, la lectura de este artículo, los supuestos que prevé y su propia terminología expresen como pocos textos legales la situación de un país $\mathrm{y}$, en este caso, la problemática realidad colombiana. Los informes de la Agencia Presidencial para la Acción Social y la Cooperación Internacional de 2012 indicaban que ese año había casi cuatro millones de desplazados en Colombia registrados en el Registro Único de Población Desplazada (es decir, que podría haber más desplazados que no se hubieran registrado). Véase MartínezSanabria y Pérez-Forero (2012, p. 115).

${ }^{7}$ La regulación constitucional colombiana de la democracia participativa se desarrolla en la ley estatutaria 131 de 1994, en la ley estatutaria 134 de 1994 y en la ley 741 de 2002. Esta legislación ha de interpretarse en relación con las sentencias C-180 de 1994 y C-011 de 1994.

${ }^{8}$ La regulación constitucional española de la democracia participativa se desarrolla en las leyes orgánicas 2 de 1980, 3 de 1984, en la Ley Orgánica 4 de 2006, 3 de 1984, 5 de 1985, 2 de 2011, y en la ley 7 de 1985 (estas tres últimas en lo relativo al concejo abierto).

${ }^{9}$ En comparación con la anterior regulación de la Constitución de 1886, se puede con- 
siderar que la Constitución de 1991 privilegia y tiene por uno de sus ejes fundamentales la democracia participativa. Véase Thomas-Acuña (2008, pp. 3, 16).

${ }^{10}$ Evidentemente, el voto puede ser visto tanto como elemento propio de la democracia representativa, como de la participativa. Siendo como es factor clave y definitorio (que no único) de la democracia, lo es tanto de la representativa, como de la participativa.

${ }^{11}$ Entender la consulta popular de este modo amplio es una postura doctrinal asumida en estas líneas, pero bien podría adoptarse otra. El Tribunal Constitucional español en sentencias como la STC 103 de 2008, del 11 de septiembre, acoge esta postura al indicar en su fundamento jurídico $2^{\circ}$ que el referendo es "una especie del género 'consulta popular' con la que no se recaba la opinión de cualquier colectivo sobre cualesquiera asuntos de interés público a través de cualesquiera procedimientos, sino aquella consulta cuyo objeto se refiere estrictamente al parecer del cuerpo electoral [expresivo de la voluntad del pueblo (STC 12 de 2008, del 29 de enero, FJ 10)] conformado y exteriorizado a través de un procedimiento electoral, esto es, basado en el censo, gestionado por la administración electoral y asegurado con garantías jurisdiccionales específicas, siempre en relación con los asuntos públicos cuya gestión, directa o indirecta, mediante el ejercicio del poder político por parte de los ciudadanos constituye el objeto del derecho fundamental reconocido por la Constitución en el artículo 23 CE [...]".

Es decir, el Tribunal Constitucional español considera que todos los referendos son consultas populares, pero no que todas las consultas populares sean referendos. Un referendo es una consulta popular caracterizada por una serie de rasgos que, en términos generales, le hacen una pregunta a los ciudadanos verdaderamente propia del derecho fundamental a la participación política del artículo $23 \mathrm{CE}$, mientras que dentro de la consulta popular se puede también considerar incluidas preguntas que no respeten los mismos requisitos y que, por ello, no sean tenidas como parte de dicho derecho fundamental, sino como manifestaciones del mucho más amplio y laxo "fenómeno participativo" al que el Tribunal Constitucional se refiere en esta misma sentencia y del que ya se ha hablado líneas atrás (STC 103 de 2008).

${ }^{12}$ Véase portal web BBC.

13 Véase portal web Registraduría Nacional del Estado Civil.

14 Véase portal web Registraduría Nacional del Estado Civil.

15 " [...] la relación electoral real no se produzca en los términos en que debería producirse, esto es, entre representante y representado, sino entre electores y partidos [...]" (Vega, 1993, p. 195).

16 "Es necesario comenzar por recordar que la Constitución del 91 no cumplió la principal expectativa para la que fue convocada, a saber, el logro de la paz y, a través de ella, la garantía de la vida. Y, sin duda, como ya se ha reconocido, más allá de sus aciertos y fortalezas en la defensa de derechos fundamentales, tampoco logró concretar lo que era otra de sus grandes aspiraciones: la de una auténtica y eficaz democracia participativa" (MejíaQuintana, 2013, p. 101).

${ }^{17}$ Artículo 6 CE: "Los partidos políticos expresan el pluralismo político, concurren a la formación y manifestación de la voluntad popular y son instrumento fundamental para la participación política. Su creación y el ejercicio de su actividad son libres dentro del respeto a la Constitución y a la ley. Su estructura interna y funcionamiento deberán ser democráticos".

${ }^{18}$ Véase Ramírez-Nárdiz (2009, pp. 167- 
19 “La Constitución española de 1978 es, de entre todas las occidentales aprobadas en los últimos cincuenta años, la más cauta frente a la figura del referendo, como instrumento de participación directa de la ciudadanía en la dirección de los asuntos públicos" (Alzaga, 1996, pp. 295-296).

\section{Referencias}

Alemán-Peñaranda, I., \& Amorocho-Martínez, F. C. (2001). Elementos de un nuevo paradigma constitucional para la sociedad colombiana. Justicia Juris, 7(2), 67-76.

Alzaga, O. (1978). Comentario sistemático a la Constitución de 1978. Madrid: Editorial del Foro.

Alzaga, O. (1996). Derecho político español según la Constitución de 1978. Madrid: Edersa.

Constitución Política (1991). Congreso de la República de Colombia. Colombia.

Decreto Legislativo 927 de 1990. Por el cual se dictan medidas tendientes al restablecimiento del orden público. Diario Oficial No. 39.335. Presidencia de la República de Colombia, mayo de 1990.

Decreto 1926 de 1990. Por el cual se dictan medidas tendientes al restablecimiento del orden público. Diario Oficial No. 39.512. Presidencia de la República de Colombia, agosto de 1990.

Fernández-Miranda, C. C., \& FernándezMiranda, C. A. (2003). Sistema electoral, partidos políticos y parlamento. Madrid: Colex.

García-Jaramillo, L. (2013). La paz como proyecto constitucional. Araucaria: Revista Iberoamericana de filosofia, política y humanidades, 29, 138-153.
Habermas, J. (1998). Facticidad y validez. Sobre el derecho y el Estado democrático de derecho en términos de teoría del discurso. Madrid: Trotta.

Kelsen, H. (1977). Esencia y valor de la democracia. Madrid: Guadarrama; Colección Punto Omega.

Leiva-Ramírez, E., \& Muñoz-González, A. L. (2011). El poder constituyente y la carta de derechos en la Constitución Política de Colombia de 1991. Administración y desarrollo, 39(54). 119-132.

Ley 131 de 1994. Por la cual se reglamenta el voto programático y se dictan otras disposiciones. Diario Oficial No. 41.351. Congreso de la República de Colombia, mayo de 1994.

Ley 134 de 1994. Por la cual se dictan normas sobre mecanismos de participación ciudadana. Diario Oficial No. 41.373. Congreso de la república de Colombia, mayo de 1994.

Ley 387 de 1997. Por la cual se adoptan medidas para la prevención del desplazamiento forzado; la atención, protección, consolidación y estabilización socioeconómica de los desplazados internos por la violencia en la República de Colombia. Diario Oficial No. 43.091. Congreso de la República de Colombia, julio de 1997.

Ley 741 de 2002. Por la cual se reforman las Leyes 131 y 134, de 1994, reglamentarias del voto programático. Diario Oficial No. 44.823. Congreso de la República, mayo de 2002 .

Manin, B. (2006). Los principios del gobierno representativo. Madrid: Alianza.

Martínez-Sanabria, C. M., \& Pérez-Forero, A. C. (2012). La restitución de tierras en 
Colombia: expectativas y retos. Revista Prolegómenos, Derechos y Valores, 15(29), 111-127.

Mejía-Quintana, O. (2013). A dos décadas de la Constitución Política de 1991. Araucaria: revista iberoamericana de filosofía, politica y humanidades, 15(29), 99-116.

Presno-Linera, M. A. (2012). El 15M y la democracia real. El Cronista del Estado Social y Democrático de Derecho, 25, 38-49.

Ramírez-Nárdiz, A. (2009). El debate en torno a los mecanismos de democracia participativa durante el proceso constituyente español. Cuadernos Constitucionales de la Cátedra Fadrique Furió Ceriol, 67-68, 167-178.

Ramírez-Nárdiz, A. (2010). Democracia participativa. La democracia participativa como profundización en la democracia. Valencia: Tirant lo Blanch.

Ramírez-Nárdiz, A. (2012). Guía práctica de la democracia participativa. Conocer la democracia participativa y aprender a usarla. Madrid: Dykinson.

Registraduría Nacional del Estado Civil (s.f.). Ranking de mecanismos de participación por departamentos. Recuperado de www. registraduria.gov.co/-Mecanismos-deParticipacion,320-.html

Reino de España. Constitución Española (1978). Congreso de los diputados. Reino de España.

Reino de España. Ley Orgánica 2 de 1980. Sobre la regulación de las distintas modalidades de referendo. Boletín Oficial del Estado No. 20 de 23 de enero de 1980. Jefatura del Estado.

Reino de España. Ley Orgánica 3 de 1984. Reguladora de la iniciativa legislativa popu- lar. Boletín oficial del Estado No. 74 de 27 de marzo de 1984. Jefatura del Estado.

Reino de España. Ley 7 de 1985. Reguladora de las bases del régimen local. Boletín Oficial del Estado No. 80 de 03 de abril de 1985. Jefatura de Estado.

Reino de España. Ley Orgánica 5 de 1985. De régimen electoral general. Boletín Oficial del Estado No. 147 de 20 de junio de 1985. Jefatura del Estado.

Reino de España. Ley Orgánica 4 de 2006. De modificación de la Ley Orgánica 3/1984, de 26 de marzo, reguladora de la iniciativa legislativa popular. Boletín oficial del Estado No. 126 de 27 de mayo de 2006. Jefatura de Estado.

Reino de España. Ley Orgánica 2 de 2011. Por la que se modifica la Ley 5/1985, de 19 de junio, de régimen electoral general. Boletín oficial del Estado No. 25 de 29 de enero de 2011. Jefatura de Estado.

Reino de España. Sentencia STC 12 (2008, febrero 29). Recurso de inconstitucionalidad. M. P. Elisa Pérez Vera. Tribunal Constitucional.

Reino de España. Sentencia STC 103 (2008, septiembre 11). Recurso de inconstitucionalidad. M. P. Guillermo Jiménez Sánchez. Tribunal Constitucional.

Sartori, G. (2003). ¿Qué es la democracia?. México D.F.: Taurus.

Schumpeter, J. A. (1971). Capitalismo, socialismo y democracia. Madrid: Aguilar.

Sentencia C-011 (1994, enero 21). Sentencia de inconstitucionalidad. M. P. Alejandro Martínez Caballero. Corte Constitucional de la República de Colombia. 
Sentencia C-180 (1994, abril 14). Sentencia de inconstitucionalidad. M. P. Hernando Herrera Vergara. Corte Constitucional de la República de Colombia.

Thomas-Acuña, E. (2008). Colombia: entre la crisis de la representatividad y la democracia directa. Zurich: C2D.

Vega de, P. (1993). La crisis de la representación política en la democracia de partidos. En R. Marguez \& M. López (Eds.), Tendencias contemporáneas del Derecho electoral en el mundo (pp. 181-204). México, D. F.: Cámara de Diputados. 